\title{
The distribution and associations of blood pressure in an adolescent population
}

\author{
TREVOR J. ORCHARD \\ From the Graduate School of Public Health, University of Pittsburgh
}

\section{A. J. HEDLEY}

From the Department of Community Health, University Hospital and Medical School, Nottingham

\section{J. R. A. MITCHELL}

From the Department of Medicine, University Hospital and Medical School, Nottingham

SUMMARY In this report we describe the distribution of blood pressure and its associations in adolescence. Six hundred and twenty-five subjects aged 13 to 18 were drawn from three general practices in different urban and rural settings. Systolic pressures were higher and rose with age in boys $(\bar{x}=119 \mathrm{~mm} \mathrm{Hg})$ compared with girls $(\bar{x}=114 \mathrm{~mm} \mathrm{Hg})$, who showed no age association. Diastolic pressures (phase 5) were higher in girls $(\overline{\mathrm{x}}=64 \mathrm{~mm} \mathrm{Hg})$ than in boys $(\overline{\mathrm{x}}=60 \mathrm{~mm} \mathrm{Hg})$ and showed no association with age in either sex. Initial blood pressures were generally higher than those recorded after a further five minutes' rest in the sitting position, although diastolic pressures rose on the second reading in the older subjects. Systolic pressures of subjects from the suburban practice and in the late autumn were relatively low; diastolic pressures tended to be lower in the spring and in subjects from the rural practice. Systolic pressures were lower in the morning and this was found to be primarily related to fasting status. Individuals with a positive family history of hypertension had significantly higher blood pressures than those with a negative history. Boys who frequently played sports had lower diastolic pressures, largely accounting for the above sex difference.

We conclude that although blood pressure measurement in adolescence is a difficult screening procedure it should be offered to selected groups such as those with a family history of hypertension.

The routine measurement of blood pressure in childhood and adolescence is a subject for debate. ${ }^{1}$ It is often part of 'office practice' in the United States of America, ${ }^{2}$ where there is a great deal of data about the distribution of blood pressure in childhood and youth, ${ }^{3-10}$ but in European practice it is the exception rather than the rule. Consequently there appears to be little recent British community-based data.

There is a growing interest in cardiovascular risk factors in childhood and adolescence, ${ }^{11}$ based largely on the premise that early detection will lead to better management and thus to lower morbidity and mortality, ${ }^{11-13}$ However, the significance and predicitive power of adolescent blood pressures remain largely unresolved. In order to provide some baseline British data, and to investigate possible determinants of cardiovascular disease risk factors, we have conducted a cross-sectional study of adolescents drawn from general practices in three different settings.

\section{Material and methods}

POPULATION SAMPLE

The subjects, aged 13 to 18 , were drawn from the registers of three general practices. Practice 1 was in suburban Nottingham, practice 2 in Nottingham city centre, and practice 3 in a semi-rural area of Derbyshire. All those currently resident in the areas of practices 1 and 3 were eligible to take part if they were aged between 13 and 18 at any time during the relevant phase of data collection; the few 12- and 
19-year-olds thus included were counted as aged 13 and 18 respectively. Practice 2 , with 9000 patients, was approximately twice as large as the others, so a one-in-two systematic age-sex stratified sample of those registered was used.

Subjects aged 16 or over were invited to participate by letter and if they agreed they were then sent an appointment. For subjects under 16, the parents were asked to return a signed consent form, on receipt of which an explanatory letter and appointment was sent to the subject. Follow-up procedures included a reminder letter and contact by telephone or home visits.

Initially 1179 teenagers were considered eligible. Of these, 154 were rejected because they were found to have moved out of the area or their date of birth was incorrect. Twenty-one subjects were excluded for medical reasons: severe mental handicap (15), recent surgery (2), Hodgkin's disease (1), late pregnancy (2), hospitalisation (1). Finally 30 subjects were chosen from practice 1 to take part in a pilot study and were therefore excluded from the main study. After these exclusions, 974 apparently healthy adolescents remained eligible, of whom $625(64 \%)$ volunteered to take part. The subjects were seen once only in specially arranged clinics which were held at their general practitioners' surgeries either on one evening or on a Saturday morning. The survey team spent two months in each practice starting in mid-November 1978 (practice 1) and ending in mid-May 1979 (practice 3).

\section{QUESTIONNAIRE}

This was completed by the subjects on arrival at the clinic and took approximately 20 minutes. It included questions on biographical details and alcohol consumption which were taken from a standardised questionnaire used in an earlier study involving adolescents from practice $1 .^{14}$ The questions about smoking behaviour were adapted from a WHO collaborative project, ${ }^{11}$ those on personal and family medical history and fibre consumption were based on the questionnaire used in the Medical Research Council/Avon Area Health Authority/St. Thomas's Speedwell Survey (Elwood PC, Sweetnam PM, Lewis B, personal correspondence 1980), and the questions on fat and cholesterol consumption were taken from the United Kingdom Heart Disease Prevention Project. ${ }^{15}$ Questions about leisure activities and sports were adapted from those used by Professor J. N. Morris, ${ }^{16}$ coded according to the oxygen consumption and energy output of each activity ${ }^{17}$ and then graded to give a five-point scale. Social class was based where possible on the occupation of the subject's father. ${ }^{18}$ The social class results for practice 1 were similar to those obtained a year previously by postal questionnaire,${ }^{14}$ suggesting an acceptable level of repeatability.

The repeatability of the questionnaire was assessed by re-inviting those who took part in the pilot study to re-attend four months later. Over $85 \%$ of the questions were answered identically, and the differences that did occur largely reflected likely seasonal variations in diet and exercise habits or the commencement of menses or shaving in the interim.

\section{EXAMINATION OF SUBJECTS}

After completing the questionnaire and resting quietly, usually for a total of about $\mathbf{3 0}$ minutes, subjects were shown into the examination room, where the first of two sets of sitting pulse and blood pressure recordings were made. Examinations were mainly performed by a doctor (T.J.O.) and a state registered nurse (J.T.) with further assistance with blood pressure recordings and venepunctures from a second doctor (A.J.H.).

The pulse, recorded before the blood pressure, was counted over 30 seconds and doubled. Blood pressure was recorded in the left arm as recommended by Rose and Blackburn ${ }^{19}$ yielding values for systolic, diastolic phase 4 , and diastolic phase 5 pressures read to the nearest $2 \mathrm{~mm}$ of mercury below. A Hawksley random-zero sphygmomanometer (Gelman Hawksley, Northampton) was used for all recordings, ${ }^{20}$ with a cuff of appropriate size as proposed by Long $e t$ al. ${ }^{21}$ The second set of pulse and blood pressure readings were taken after a further five minutes sitting, during which any problems arising from the completion of the questionnaire were resolved and efforts were made to put the subject at ease. It was hoped that the first set of readings would resemble an actual GP consultation, and that the second would be consistent with standard epidemiological survey methods. Both sets of blood pressures were recorded by one observer only for any given individual. The two observers (T.J.O. and J.T.) who examined $90 \%$ of the subjects did so without regard to the sex of the individual.

Standing height was measured in centimetres to the nearest $0 \cdot 1 \mathrm{~cm}$ using a portable Harpenden stadiometer in a standardised fashion. ${ }^{1122}$ Weight was measured using an Avery balance scale in $\mathrm{kg}$, to the nearest $100 \mathrm{~g}$ below, subjects wearing only underwear. The stadiometer and balance were calibrated before each clinic. Triceps and subscapular skinfold thicknesses were recorded to the nearest $0.1 \mathrm{~mm}$ using the Harpenden skin calipers in accordance with standard procedure. ${ }^{11} 22$ Sexual maturity was assessed in boys by T.J.O. using Tanner's pubertal ratings ${ }^{22}$ for pubic hair and genital 
development; sexual maturity of the girls for pubic hair and breast development was similarly assessed ${ }^{22}$ by J.T. Subjects attending on Saturday mornings (self-selected) were asked to fast during the previous 12 hours. On completion of the examination approximately $25 \mathrm{ml}$ of venous blood was obtained by venepuncture from the antecubital fossa.

The two principal examiners (T.J.O. and J.T.) underwent a two-month training period during which repeatability and interobserver variations of anthropometric and blood pressure recordings were assessed and variation minimised.

Intraobserver repeatability of skinfold measurements was achieved within the guidelines suggested by Edwards. ${ }^{23}$ Throughout the main study, duplicate measurements were made by both the principal examiners on a randomly chosen subject in each clinic; the relative mean differences for T.J.O.'s readings minus J.T.'s were $-2 \cdot 4 \%$ for triceps and $-0.25 \%$ for subscapular skinfold thicknesses. The readings in $\mathrm{mm}$ were transformed to a logarithmic scale before analysis (to give a normal distribution in accordance with standard procedure ${ }^{23}$ ) so these differences represent less than a $0.5 \%$ difference in the resulting log values.

The training for the blood pressure recordings included familiarisation exercises with the Hawksley random-zero sphygmomanometer, the use of prerecorded Korotkoff sounds, and the repeated use of a stethoscope with two sets of ear-pieces, for simultaneous measurements of blood pressure by two observers. Intraobserver variation using the prerecorded Korotkoff sounds was assessed by the use of blind duplicate recordings; the mean difference of such readings was less than $3 \%$ for each of the three examiners. During each clinic the double-headed stethoscope was used by all appropriate pairings of observers present on randomly chosen individuals; the relative mean percentage difference for T.J.O.-J.T. (who between them made $90 \%$ of all blood pressure recordings) was +0.5 (systolic), -0.9 (diastolic phase 4$)$ and +1.2 (diastolic phase 5).

\section{STATISTICAL ANALYSIS}

All distributions and percentiles are based on the whole population. However, in order to study the determinants and correlates of the riskfactors, subjects who were on drugs (apart from oral contraceptives) known to interfere with lipid metabolism, and all non-white participants, were excluded from subsequent analyses. This reduced the population to approximately 590 .

As $40 \%$ of the population had a brother or sister in the study, it could be argued that the subjects are not all 'independent' and therefore the analyses are invalid. All major relationships were therefore analysed on the basis of a smaller population, (random-sibling population), comprising only one individual, selected at random, from each family; no major differences were detected.

Statistical tests of significance, unless otherwise stated, were either $\chi^{2}$ (for qualitative variables) or one-way analyses of variance (for quantitative measures) when comparing groups. For two groups the latter is equivalent to an unpaired Student's $t$ test, which, for large degrees of freedom, is approximated by a standard normal deviate, and in this case the exact degrees of freedom are not given in the Tables. Correlation coefficients were all Pearson product-moment coefficients unless otherwise stated, and their significance was determined by transformation to Student's $t$ statistic. ${ }^{24}$

Age-sex standardisation was achieved by the use of ' $Z$ ' scores, ${ }^{24}$ (original value-group mean)/group standard deviation.

\section{Results}

\section{RESPONSE}

The response varied mainly with practice and age. It was higher in practice 2 and among the younger adolescents, although there was also a small sex difference. Ninety-six per cent of those taking part were British-born whites; the largest minority group comprised 16 West Indians. Some 30\% had left school, indicating the broader population available to community-based compared with school-based studies in this age group.

\section{DRUG AND ALCOHOL USAGE}

Seventeen per cent were currently taking medicine of some sort, including the contraceptive pill, which was used by a quarter of all 16-18-year-old girls. Similar proportions of boys and girls $(44 \%$ and $39 \%$ respectively) consumed alcohol on a regular basis, that is, at least once a week, but boys drank considerably more by volume than girls $-49.7 \mathrm{ml}$ compared with $21.9 \mathrm{ml}$ a week $(\mathrm{t}=4.37$; $\mathrm{p}<0.001)$.

\section{PHYSICAL ACTIVITY}

Boys and younger adolescents obtained higher sports scores than girls and older subjects $\left(\chi^{2}=77 \cdot 1\right.$, $\mathrm{p}<0.001$ with $4 \mathrm{df}$ and $\chi^{2}=45.4, \mathrm{p}<0.001$ with 4 df).

BLOOD PRESSURE

Tables 1 and 2 show the distribution of blood pressure by age and sex. The mean of the two 
Table 1 Means, standard deviations (SD), and percentiles of systolic blood pressure by age and sex

\begin{tabular}{|c|c|c|c|c|c|c|c|c|c|c|c|c|c|c|c|c|}
\hline \multirow[b]{3}{*}{ Age } & \multicolumn{8}{|c|}{$M A L E$} & \multicolumn{8}{|c|}{ FEMALE } \\
\hline & \multirow[b]{2}{*}{$\bar{x}$} & \multirow[b]{2}{*}{$S D$} & \multicolumn{5}{|c|}{ Percentile } & \multirow[b]{2}{*}{ No. } & \multirow[b]{2}{*}{$\bar{x}$} & \multirow[b]{2}{*}{$S D$} & \multicolumn{5}{|c|}{ Percentile } & \multirow[b]{2}{*}{ No. } \\
\hline & & & 5th & 10th & 50 th & $90 t h$ & 95th & & & & $5 t h$ & 10th & SOth & $90 t h$ & 95th & \\
\hline 13 & $113 \cdot 3$ & $12 \cdot 7$ & 94 & 98 & 115 & 128 & 132 & 63 & 114.4 & $13 \cdot 1$ & 93 & 99 & 114 & 133 & 138 & 56 \\
\hline 14 & $114 \cdot 3$ & $15 \cdot 0$ & 95 & 97 & 112 & 136 & 139 & 75 & 113.4 & $11 \cdot 7$ & 93 & 100 & 112 & 128 & 131 & 52 \\
\hline 15 & $122 \cdot 9$ & $14 \cdot 2$ & 100 & 107 & 122 & 139 & 154 & 54 & 113.6 & $9 \cdot 3$ & 97 & 103 & 115 & 125 & 130 & 52 \\
\hline 16 & $122 \cdot 6$ & $10 \cdot 8$ & 105 & 108 & 123 & 138 & 140 & 43 & 112.9 & $10 \cdot 5$ & 97 & 98 & 112 & 124 & 132 & 49 \\
\hline 17 & $119 \cdot 2$ & $13 \cdot 8$ & 94 & 100 & 118 & 136 & 140 & 40 & 114.9 & $10 \cdot 8$ & 95 & 100 & 114 & 129 & 132 & 50 \\
\hline 18 & $127 \cdot 9$ & $15 \cdot 2$ & 107 & 114 & 129 & 144 & 144 & 44 & 113.6 & $9 \cdot 5$ & 101 & 103 & 113 & 127 & 134 & 47 \\
\hline All ages & $119 \cdot 1$ & 14.6 & 96 & 100 & 119 & 138 & 143 & 319 & 113.6 & $10 \cdot 9$ & 97 & 101 & 114 & 129 & 132 & 306 \\
\hline \multicolumn{4}{|c|}{$\begin{array}{c}\text { Systolic differences male v. female } \\
\text { With age (male) } \\
\text { With age (female) } \\
\text { Age (male + female) }\end{array}$} & & $\begin{aligned} & 5 \cdot 36 \\
= & 8 \cdot 97 \\
= & 0 \cdot 43 \\
= & 4 \cdot 12\end{aligned}$ & \multicolumn{3}{|c|}{$\begin{array}{ll}p<0.001 & \\
p<0.001 & 5 \mathrm{df} \\
\text { NS } & 5 \mathrm{df} \\
\mathrm{p}<0.001 & 5 \mathrm{df}\end{array}$} & & & & & & & & \\
\hline
\end{tabular}

Table 2 Means, standard deviations (SD), and percentiles of diastolic phase 5 blood pressure by age and sex

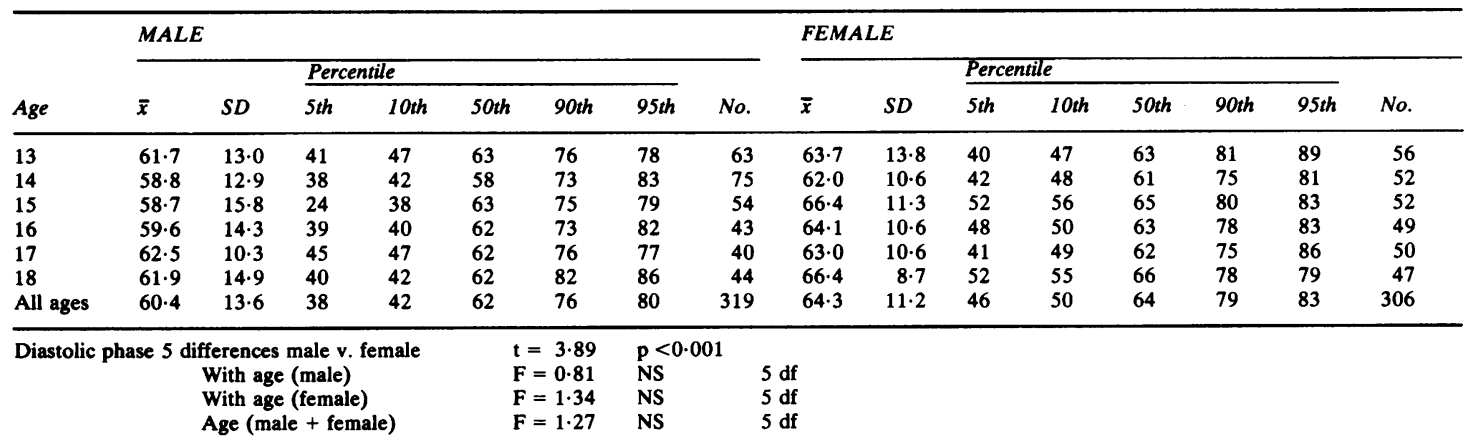

pressures recorded on each subject was used for these analyses.

Higher systolic blood pressures were found in boys at older ages but in girls there was little age variation. Although showing some variation in diastolic pressure with age, girls tended to have higher diastolic pressures than boys, and this difference was highly significant for diastolic pressure phase 5 $(\mathrm{p}<0.001)$. Girls also had higher pulse rates than boys ( 82 compared with 77 beats a minute; $<p 0.05$ ).

Overall, the effect of a further five minutes of seated rest (Table 3 ) was to decrease the systolic and

Table 3 Difference between first and second recordings of pulse rate and blood pressure

\begin{tabular}{|c|c|c|c|c|c|c|}
\hline & & \multicolumn{2}{|c|}{ Age groups (years) } & \multicolumn{2}{|l|}{$\operatorname{Sex}$} & \multirow{2}{*}{$\frac{A l l}{13-18}$} \\
\hline & & $13-15$ & $16-18$ & Male & Female & \\
\hline \multirow[t]{2}{*}{ Pulse } & $1 \mathrm{st}$ & 79.8 & $77 \cdot 4$ & $76 \cdot 0$ & $81 \cdot 7$ & $78 \cdot 8$ \\
\hline & 2nd & $82 \cdot 0$ & $77 \cdot 7$ & $78 \cdot 1$ & $82 \cdot 3$ & $80 \cdot 1$ \\
\hline \multirow[t]{2}{*}{ Systolic } & 1 st & $116 \cdot 6$ & $120 \cdot 3$ & $120 \cdot 7$ & $118 \cdot 6$ & $118 \cdot 2$ \\
\hline & 2nd & 113.7 & $116 \cdot 1$ & $117 \cdot 0$ & 112.4 & 114.8 \\
\hline $\begin{array}{l}\text { Diastolic } \\
\text { (phase 5) }\end{array}$ & $\begin{array}{l}\text { 1st } \\
\text { 2nd }\end{array}$ & $\begin{array}{l}61.9 \\
60.9\end{array}$ & $\begin{array}{l}62.4 \\
63.9\end{array}$ & $\begin{array}{l}60 \cdot 1 \\
60 \cdot 2\end{array}$ & $\begin{array}{l}64 \cdot 2 \\
64 \cdot 3\end{array}$ & $\begin{array}{l}62 \cdot 1 \\
62 \cdot 3\end{array}$ \\
\hline
\end{tabular}

diastolic pressures in the younger participants; in the older age group it was only the systolic pressures that fell, and the diastolic pressures rose. Pulse rates rose in younger subjects of each sex, suggesting increased anxiety during the second reading. The correlation coefficients between the two readings were fairly constant for all pressures, ranging from 0.5 to 0.8 . Although the variations in the means of the first and second recordings were fairly small, there was a large range of individual differences for each pressure. For example, systolic pressure rose by $38 \mathrm{~mm} \mathrm{Hg}$ in one case, and fell by $76 \mathrm{~mm} \mathrm{Hg}$ in another, and the differences between the two readings of diastolic pressure ranged from an increase of $48 \mathrm{~mm} \mathrm{Hg}$ to a decrease of $54 \mathrm{~mm} \mathrm{Hg}$. Pulse rates rose by up to 34 beats a minute and fell by as much as 40 beats a minute.

Pulse rate and systolic blood pressure also varied with time of day and with fasting status (Table 4). Age and sex standardisation failed to remove these effects. Comparisons of fasting and non-fasting subjects and morning or evening attendances showed that fasting status was the predominant factor, since 
non-fasting subjects had similar diastolic pressures in both morning and evening.

A positive family history of blood pressure in siblings, parents, and parents' siblings $(15 \%$ of our sample) was associated with higher systolic and diastolic pressures (Table 5) but not with any differences in pulse rates.

Regular cigarette smoking was not related to pulse rate or blood pressure, except for mean systolic pressure in girls, which was lower among smokers $(110.5 \mathrm{~mm} \mathrm{Hg})$ than non-smokers $(114.8 \mathrm{~mm} \mathrm{Hg})$ $(t=2.62 ; 0.01>p>0.001)$. Similarly, regular consumption of alcohol was not related to blood pressure, except for a higher systolic pressure among boys, which was not significant after age standardisation. Among smokers and drinkers the amounts of tobacco and alcohol consumed were not correlated with blood pressure. Among 16-18-year old girls, users of the pill had blood pressures similar to those of non-users.

Sports activity was strongly and inversely related to diastolic pressures for boys (Table 6) although no such relationship was noted for girls or for systolic pressure in either sex. Pulse rate in boys was also inversely related to sports activity. These associations were independent of age.

The influence of anthropometric and maturity variables on age-standardised blood pressure was seen almost exclusively in boys, and only for systolic pressure (for example, systolic blood pressure with height $r=0.16,0.01>p>0.001$; with weight $r=0 \cdot 20,0 \cdot 01>p<0 \cdot 001$; with skinfold $r=0 \cdot 15$, $0.01>p>0.001$; with genital stage $r=0 \cdot 14,0 \cdot 01>$ $p>0.001)$. However, weak correlations were seen for skinfold with diastolic pressure in girls $(r=0 \cdot 12$, $0.05>p>0.01$ ) and with diastolic phase 4 readings in boys $(r=0.10,0.05>p>0.01)$. The

Table 4 Mean pulse rate and blood pressure values by morning or evening clinic attendance and fasting status

\begin{tabular}{|c|c|c|c|c|}
\hline & \multirow[b]{2}{*}{$\begin{array}{l}\text { Pulse rate } \\
\text { beats/minute }\end{array}$} & \multicolumn{2}{|c|}{ Blood pressure $(\mathrm{mm} \mathrm{Hg})$} & \multirow[b]{2}{*}{ No. } \\
\hline & & Systolic & $\begin{array}{l}\text { Diastolic } \\
\text { phase } 5\end{array}$ & \\
\hline Morning a & $77 \cdot 6$ & $114 \cdot 0$ & $63 \cdot 1$ & 201 \\
\hline Evening $^{\mathrm{a}}$ & $80 \cdot 5$ & $117 \cdot 8$ & $61 \cdot 7$ & 381 \\
\hline Fasted ${ }^{6}$ & $77 \cdot 3$ & 113.5 & 63.9 & 160 \\
\hline Non-fasted total ${ }^{b}$ & $80 \cdot 3$ & $117 \cdot 6$ & 61.6 & 429 \\
\hline Non-fasted morning $\mathrm{c}$ & $78 \cdot 4$ & $115 \cdot 5$ & $60 \cdot 5$ & 48 \\
\hline Non-fasted evening $\mathrm{c}$ & $80 \cdot 5$ & $117 \cdot 9$ & $61 \cdot 7$ & 380 \\
\hline
\end{tabular}

a Significant associations

Systolic: morning v. evening $t=3.3858 \quad p<0.001$

Pulse: morning v. evening $t=2.7033 \quad 0.01>p>0.001$

bignificant associations

Systolic: fasted v. non fasted $t=3.4074 \quad p<0.001$

Pulse: fasted v. non fasted $t=2.6027 \quad 0.01>p>0.001$

c Associations all non-significant (Systolic morning $v$. evening $t=1 \cdot 1452$

or $t=1.4625$ age and sex-standardised)

Table 5 Blood pressure values and pulse rate (beats a minute) by family history

\begin{tabular}{lccl}
\hline & \multicolumn{3}{l}{ Family history of blood pressure } \\
\cline { 2 - 3 } & Positive & Negative & $\begin{array}{l}\text { Unpaired } \\
\text { t test }\end{array}$ \\
\hline Systolic & 119.2 & 116.0 & $t=2.1507^{*}$ \\
Diastolic (phase 5) & 65.3 & 61.6 & $t=2 \cdot 5362^{*}$ \\
Pulse & 79.9 & 79.4 & $t=03669$ \\
\hline
\end{tabular}

$0.05>p>0.01$

intercorrelations of the blood pressures showed strong associations between the two diastolic readings $(r=0 \cdot 88, p<0 \cdot 001)$ but low correlations between them and the systolic pressures $(r=0 \cdot 28$, $\mathrm{p}<0.001$ for diastolic phase 4 and $\mathrm{r}=0.18$, $\mathrm{p}<0.001$ for diastolic phase 5).

Table 6 Blood pressure values and pulse rate (beats a minute) by sports activity score by sex (standardised for age and sex)

\begin{tabular}{ccccc} 
(Low) & Sports activity score & & (High) \\
\hline 1 & 2 & 3 & 4 & 5
\end{tabular}

No. SIGNIFICANCE
SI

\begin{tabular}{|c|c|c|c|c|c|c|c|}
\hline \multirow[b]{2}{*}{ MALES } & \multicolumn{5}{|l|}{ No. } & \multicolumn{2}{|c|}{ SIGNIFICANCE } \\
\hline & 21 & 52 & 94 & 64 & 70 & (Crude data) & $\begin{array}{l}\text { (Standardised } \\
\text { data) }\end{array}$ \\
\hline $\begin{array}{l}\text { Systolic } \\
\text { Diastolic (phase 5) } \\
\text { Pulse }\end{array}$ & $\begin{array}{r}124 \cdot 1 \\
70 \cdot 1 \\
77 \cdot 0\end{array}$ & $\begin{array}{r}119 \cdot 3 \\
61 \cdot 3 \\
80 \cdot 4\end{array}$ & $\begin{array}{r}119 \cdot 4 \\
59 \cdot 7 \\
78 \cdot 5\end{array}$ & $\begin{array}{r}115 \cdot 0 \\
61 \cdot 2 \\
75 \cdot 3\end{array}$ & $\begin{array}{r}119 \cdot 7 \\
56 \cdot 1 \\
74 \cdot 4\end{array}$ & $\begin{array}{l}\mathbf{F}=1.8696 \mathrm{NS} \\
\mathbf{F}=4.9731^{* * *} \\
\mathbf{F}=2.5884^{*}\end{array}$ & $\begin{array}{l}1 \cdot 7435 \\
4 \cdot 1186^{* * *} \\
2 \cdot 5477^{*}\end{array}$ \\
\hline
\end{tabular}

No.

\begin{tabular}{|c|c|c|c|c|c|c|c|}
\hline \multirow[b]{2}{*}{ FEMALES } & & & \\
\hline & (64) & $(82)$ & (95) & (23) & (23) & & \\
\hline $\begin{array}{l}\text { Systolic } \\
\text { Diastolic (phase 5) } \\
\text { Pulse }\end{array}$ & $\begin{array}{r}113 \cdot 1 \\
65 \cdot 7 \\
81 \cdot 7\end{array}$ & $\begin{array}{r}113 \cdot 5 \\
63 \cdot 6 \\
82 \cdot 6\end{array}$ & $\begin{array}{r}115 \cdot 1 \\
64 \cdot 7 \\
82 \cdot 7\end{array}$ & $\begin{array}{r}112 \cdot 3 \\
60 \cdot 3 \\
80 \cdot 7\end{array}$ & $\begin{array}{r}115 \cdot 6 \\
64 \cdot 8 \\
78 \cdot 9\end{array}$ & $\begin{array}{l}F=0.6340 \mathrm{NS} \\
F=1.1341 \mathrm{NS} \\
F=0.5581 \mathrm{NS}\end{array}$ & $\begin{array}{l}0.7996 \\
0.9894 \\
0.5606\end{array}$ \\
\hline
\end{tabular}

$0.05>p>0.01$

***p<0.001 


\section{Discussion}

Our systolic blood pressures (Table 1) are generally comparable to those of American studies. Although our values are about $4 \mathrm{~mm} \mathrm{Hg}$ higher than the National Health Examination Survey of 1971-4 they are considerably lower than the earlier 1966-70 results from the same source..$^{25}$ Data from St. Louis, which includes some blacks, show somewhat higher values, especially for girls, ${ }^{2}$ as do the Evans County ${ }^{4}$ and Muscatine studies. ${ }^{7}$ However, data from Boston, ${ }^{5}$ New York, ${ }^{6}$ and Cologne ${ }^{26}$ show similar values. All these studies show the association with age of higher systolic pressures during male adolescence, and no such change in females, as seen in our results.

Our diastolic pressures (Table 2) are approximately the same as, or just $2-5 \mathrm{~mm} \mathrm{Hg}$ lower than, the values in these other studies, with the exception of the phase 5 diastolic pressures from Boston, ${ }^{5}$ which are about $10 \mathrm{~mm} \mathrm{Hg}$ lower than our values but were based on half as many persons. The tendency in our study for girls to have slightly higher diastolic readings than boys is not seen in the National Health Examination Survey, ${ }^{3}$ nor in the New York study, ${ }^{6}$ but it is a feature of the Boston study. ${ }^{5}$

In this study we wanted to see the effect of measuring blood pressure immediately on entry to the consulting room and then after a five-minute 'consultation', for it is likely that many blood pressures are recorded in the former manner. The overall difference in the mean suggests that pressures are likely to be slightly lower on repetition, except for the older subjects, whose diastolic pressures rise. However, the consistent increase in pulse rate in the younger age group suggests, as did some of the comments made by our subjects, that some disliked having their pressure taken and became anxious when they realised it was about to happen again. Anxiety is not reflected in the blood pressure recordings, except possibly in older subjects who had a slight rise in diastolic pressure. The differences noted in Table 3 may, therefore, reflect not only the effect of five minutes' rest in the sitting position but also the anxiety caused by recently having had one's blood pressure recorded. The range of differences was large in some individuals: $20 \mathrm{~mm} \mathrm{Hg}$ changes in either direction were commonplace, showing that no systematic variation existed. A high variability of blood pressures is a common finding in this age group. ${ }^{2567}$

The lower systolic pressures in the morning appeared to be largely dependent on fasting status (Table 4). Diurnal variation of blood pressure is well-known, though the variation seen in this study is more consistent with the earlier indirect blood pressure recordings ${ }^{27}$ than with recent intra-arterial studies. ${ }^{28}$ Comparisons are difficult because of the problem of fasting status, which we recommend should now be stated in all future reports. As there was no variation between fasting status and any other important factor, except triglyceride values, we have not introduced any compensation for fasting values.

A positive family history of blood pressure was associated with higher blood pressure, a finding which is consistent with the known familial aggregation of blood pressure ${ }^{5930}$ and a useful pointer to who should be screened. The association between sports activity and diastolic blood pressure was independent of practice, age, weight, height, and Quetelet index. The Tecumseh study reported similar data largely based on older subjects. ${ }^{31}$ The small association between alcohol and male systolic blood pressures did not remain after age standardisation, therefore we are unable to provide support for the supposed association between alcohol and blood pressure, although a longer exposure to higher consumption than our subjects experienced might be needed. Our data did not show an association between blood pressure and anthropometric variables as strong as that from Bogalusa ${ }^{32}$ on a younger age group ( 5 to 14 ), or from Evans County on an older age group (15 to 29). ${ }^{4}$ However, significant correlations were seen for boys between systolic blood pressure and height, weight, skinfold thickness, and Quetelet index and for girls with skinfold thickness. Factors that may be related to the differences between our results and these two other studies include the different age groups studied and blood pressure recordings used ('basal' blood pressure in Bogalusa ${ }^{32}$ and the initial reading in Evans County ${ }^{4}$ ).

Age, as in Bogalusa, ${ }^{32}$ was a relatively weak associate of blood pressure, though a significant correlation was seen for systolic blood pressure in males $(r=0.30, p<0.001)$. Height, weight, and various measures of obesity are also shown in other studies to be important determinants of blood pressure in this age group. ${ }^{2-5}{ }^{29}$ We suggest that sexual development be added to the list because with systolic blood pressure it provided the only significant partial correlation $(r=0.10,0.05>$ $p>0.01$ ) of any blood pressure in the boys when the anthropometric variables were included in the analyses. The only significant partial correlate of any developmental variable for any pressure level in girls was between skinfold thickness and diastolic pressure (fifth phase), an association that was much weaker in univariate analysis. Although significant simple correlations between all three blood pressures were seen, the coefficients were fairly low $(r=0 \cdot 3)$ for 
systolic pressure with either diastolic pressure level, suggesting that systolic and diastolic pressures should be considered separately in this age group. The Dormont High School study ${ }^{33}$ showed similar correlations between systolic and diastolic pressures at age 17, while 17 years later the coefficients had doubled in both sexes.

Various studies, both retrospective $e^{33} 34$ and prospective, ${ }^{1035}$ have shown some degree of 'tracking' and significant correlations for repeated blood pressures first recorded in adolescence or young adulthood and then repeated later, but the coefficients are low (in some cases below 0.20). Furthermore, our study has shown that great variability exists between duplicate readings even within five minutes of the initial examination. We conclude that screening adolescents is unlikely to identify a high-risk group of individuals for future hypertensive-related morbidity, except those with a positive family history who, as we have shown, are likely to have higher pressures. Using the data from the Dormont High School Study, ${ }^{33}$ only three individuals out of 18 identified at age 17 as being in the top decile for systolic blood pressure were similarly placed 17 years later. Consequently the method lacks specificity. Because the risk attached, in terms of coronary heart disease, is itself only moderate (for example, Framingham, ${ }^{36}$ where the top decile of risk provides less than a quarter of coronary heart disease experience), much expense and unwarranted anxiety may be caused. Clearly, adolescents who are found to have higher blood pressures than their peers after allowing for development should be considered for repeated assessment, and if continually 'hypertensive' they should be advised where appropriate to lose weight and take more exercise because these factors may help to lower blood pressure. A clearer understanding of the determinants of adolescent blood pressure, in particular why systolic pressures rise in boys and not in girls, may also provide clues to why males seem particularly prone to cardiovascular disease, and would be useful in determining prescriptive screening policies.

We conclude that blood pressure screening programmes for adolescents should only be undertaken cautiously with adequate provision for repeated standardised recordings over time. Careful studies documenting the effects of intervention limited to simple measures (for example, weight loss, dietary salt reduction, and increased amounts of exercise) are needed. Meanwhile, the screening of adolescents who are first-degree relatives of hypertensives would seem to be a more rational approach, for, as our study has shown, they have on average higher blood pressures. They are more likely to yield cases above a designated cut-off level, such as the 95th percentile for the whole population. However, even such a selective approach would yield only few 'positives' with pressures above the cut-off level. For example, using the data from Table 2, a shift in the overall distribution by $3 \mathrm{~mm} \mathrm{Hg}$ (the overall mean difference between relatives of hypertensives and non-relatives) would mean, assuming a similar frequency distribution, that $10 \%$ of the screened population would have values above the cut-off level, as opposed to $5 \%$ of the total population. Although such a policy would double the yield per screened child and reduce the number of children to be screened by $85 \%$, two-thirds of those above the 95th percentile would be undetected because they would be in the unscreened population.

A number of similar decision rules could be formulated and considered in conjunction with the probable costs and benefits. Finally, long-term studies would be required to estimate the predictive accuracy of the chosen screening procedure in relation to the long-term outcome measured in terms of the morbidity and mortality experienced by screened and unscreened groups-including those for whom intervention takes place and appropriate comparison groups.

This research was supported by Grant No. 619 from the British Heart Foundation which also provided a research fellowship for Trevor J. Orchard. We thank Ms. Jean Thomas SRN, Dr. G. Walker (Department of Clinical Biochemistry, University Hospital, Nottingham) for providing laboratory facilities, and Dr. David Spiegelhalter and Mr. Neville Hunt (Department of Mathematics, University of Nottingham) for assistance with the analyses.

Data on diastolic pressures based on the fourth Korotkoff sound are available from the authors on request.

Reprints from Dr. A. J. Hedley, Department of Community Health, University Hospital and Medical School, Nottingham NG7 2UH.

\section{References}

${ }^{1}$ Anonymous. Hypertension in childhood. Lancet 1979; ii: 833-4.

${ }^{2}$ Londe S. Blood pressure in children as determined under office conditions. Clin Pediatr 1966; 5: 71-8. 
${ }^{3}$ US Department of Health Education and Welfare. National Health Examination Survey. Blood pressure levels of persons 6-74 years. United States 1971-1974. V.S. Series 11, No. 203. DHEW Publication Number (HRN) 78-1648. Washington DC: US Government Printing Office, 1978.

4 Johnson AL, Cornoni JC, Cassel JC, Tyroler HA, Heyden $\mathrm{S}$, Hames GG. Influence of race, sex and weight on blood pressure behaviour in young adults. Am J Cardiol 1975; 35: 523-30.

${ }^{5}$ Zinner SH, Martin LF, Sacks F, et al. A longitudinal study of blood pressure in childhood. Am J Epidemiol 1975; 100: 437-42.

${ }^{6}$ Kilcoyne MM. In: New M, Levine I, eds. Juvenile hypertension. New York: Raven Press, 1977: 22-35.

'Lauer RM, Connor WE, Leaverton PE, Reiter MA, Clarke WR. Coronary heart disease risk factors in school children. The Muscatine study, J Pediatr 1975; 86: 697-706.

${ }^{8}$ Voors AW, Webber LS, Frerichs RA, Berenson CS. Body height and body mass as determinants of basal blood pressure in children. The Bogalusa heart study. Am J Epidemiol 1977; 106: 101-8.

${ }^{9}$ Shear CL, Frerichs RR, Weinberg R, Berenson CS. Childhood sibling aggregation of coronary artery disease risk factors variables in a biracial community. Am J Epidemiol 1978; 107: 522-8.

${ }^{10}$ Buck C. The persistence of elevated blood pressure first observed at age five. J Chronic Dis 1973; 26: 101-4.

${ }^{11}$ World Health Organisation. WHO/ISFC meeting on precursors of atherosclerosis in children. CVD 78/1. Geneva: WHO, 1977.

${ }^{12}$ Blumenthal S. Prevention of atherosclerosis. Am J Cardiol 1973; 31: 591-4.

${ }^{13}$ Lloyd JK, Wolf HJ. A paediatric approach to the prevention of atherosclerosis. Atherosclerosis Research 1969; 10: 135-8.

${ }^{14}$ Orchard TJ. The counselling needs, health and personal problems of adolescents. MMedSci thesis. Nottingham: University of Nottingham, 1978.

${ }^{15}$ Heller RF, Tunstall Pedoe HD, Christie GDA, Rose G. Influence of dietary change on plasma cholesterol in the UK Heart Disease Prevention Project. Transactions of the European Society of Cardiology 1978; 1: 59.

${ }^{16}$ Morris JN, Chave SO, Adam C, Sivey C. Vigorous exercise in leisure time and the incidence of coronary heart disease. Lancet 1973; i: 333-9.

${ }^{17}$ Astrand PO, Rodahl K. Textbook of work physiology. New York; McGraw Hill, 1970.

${ }^{18}$ Registrar General. Classification of occupations. London: HMSO, 1970.

${ }^{19}$ Rose GA, Blackburn H. Cardiovascular survey methods. Geneva: WHO, 1968.
${ }^{20}$ Wright BM, Dore CG. A random zero sphygmomanometer. Lancet 1970; i: 337.

${ }^{21}$ Long M, Dunlop JR, Holland WW. Blood pressure recording in children. Arch Dis Child 1971; 46: 636-40.

${ }^{22}$ Tanner JM. Growth at adolescence. Oxford: Blackwell Scientific Publications, 1962.

${ }^{23}$ Edwards DAW. Design and accuracy of calipers for measuring subcutaneous tissue thickness. $\mathrm{Br} J \mathrm{Nutr}$ 1955; 9: 133-43.

${ }^{24}$ Nie NH, Hull CH, Jenkins JB, Steinbrenner K, Brent DH. Statistical package for the social sciences, 2nd edn. New York: McGraw Hill, 1975.

${ }^{25}$ US Department of Health, Education and Welfare. National Health Examination Survey. Blood pressure of youths 12-17 years. United States 1966-1970. V.S. Series 163, DHEW Publication Number (HRA) 77-1645. Washington: US Government Printing Office.

${ }^{26}$ Laaser U, Schüt A. The cardiovascular risk profile of adolescents in Cologne. A representative study including 6302 pupils. Z Kardiol 1978; 67: 837-46.

${ }^{27}$ Stamler J, Stamler R, Pullman TN. The epidemiology of hypertension. New York: Grune and Stratton, 1967.

${ }^{28}$ Craig MWM, Bishop CN, Raftery EB. Circadian variation of blood pressure. Lancet 1978; ii: 795-7.

${ }^{29} \mathrm{Kotchen} \mathrm{JM}$. Effect of relative weight on familial blood pressure aggregation. Am J Epidemiol 1977; 105: 214-21.

${ }^{30}$ Feinlieb M. In: Epidemiology and control of hypertension, Paul C, ed. New York; Stratton, 1975.

${ }^{31}$ Montye HJ. Physical activity and health. An epidemiologic study of an entire community, New Jersey. New York: Prentice Hall, 1975.

${ }^{32}$ Voors AW, Webber LS, Frerichs RR, Berenson GS. Body height and body mass on determinants of basal blood pressure in children. The Bogalusa heart study. Am J Epidemiol 1977; 196: 101-8.

${ }^{33}$ Kuller LH, Crook M, Alman MJ, Detre K, Reese G, Rutan G. Dormont High School, Pittsburgh, Pa; Blood Pressure Study. Hypertension 1980; 2: 109-16.

${ }^{34}$ Paffenbarger RS, Wing AL. Chronic disease in former college students. The effects of single and multiple characteristics on risk of fatal coronary heart disease, Am J Epidemiol 1969; 90: 527-35.

${ }^{35}$ Clarke WR, Schrott HG, Leaverton PE, Conner WE, Lauer RM. Tracking of blood lipids and blood pressures in school-age children. The Muscatine study. Circulation 1978; 58: 626-34.

${ }^{36}$ Kannel WB, McGee D, Gordon T. A general cardiovascular risk profile. The Framingham study. Am J Cardiol 1976; 38: 46-51. 